\title{
Sost Haploinsufficiency Provokes Peracute Lethal Cardiac Tamponade without Rescuing the Osteopenia in a Mouse Model of Excess Glucocorticoids
}

\author{
Behzad Javaheri, ${ }^{*}$ Eleanor Herbert, ${ }^{* \dagger}$ Mark Hopkinson, ${ }^{*}$ Ahmed Al-Jazzar, ${ }^{\ddagger}$ and Andrew A. Pitsillides ${ }^{*}$ \\ From the Department of Comparative Biomedical Sciences, $*$ The Royal Veterinary College, London, United Kingdom; Experimental Histopathology, ${ }^{\dagger}$ The \\ Francis Crick Institute, London, United Kingdom; and the College of Veterinary Medicine, ${ }^{\ddagger}$ King Faisal University, Al-Hofuf, Saudi Arabia
}

\author{
Accepted for publication \\ December 7, 2018. \\ Address correspondence to \\ Andrew A. Pitsillides, Ph.D., \\ Department of Comparative \\ Biomedical Sciences, The \\ Royal Veterinary College, \\ Royal College St., London \\ NW1 0TU, United King- \\ dom. E-mail: apitsillides@rvc. \\ ac.uk.
}

\begin{abstract}
Glucocorticoid-induced secondary osteoporosis is the most predictable side effect of this antiinflammatory. One of the main mechanisms by which glucocorticoids achieve such deleterious outcome in bone is by antagonizing Wnt/ $\beta$-catenin signaling. Sclerostin, encoded by Sost gene, is the main negative regulator of the proformative and antiresorptive role of the Wnt signaling pathway in the skeleton. It was hypothesized that the partial inactivation of sclerostin function by genetic manipulation will rescue the osteopenia induced by high endogenous glucocorticoid levels. Sost-deficient mice were crossed with an established mouse model of excess glucocorticoids, and the effects on bone mass and structure were evaluated. Sost haploinsufficiency did not rescue the low bone mass induced by high glucocorticoids. Intriguingly, the critical manifestation of Sost deficiency combined with glucocorticoid excess was sporadic, sudden, unprovoked, and nonconvulsive death. Detailed histopathologic analysis in a wide range of tissues identified peracute hemopericardium and cardiac tamponade to be the cause. These preclinical studies reveal outcomes with direct relevance to ongoing clinical trials that explore the use of antisclerostin antibodies as a treatment for osteoporosis. They particularly highlight a potential for increased cardiovascular risk and may inform improved stratification of patients who might otherwise benefit from antisclerostin antibody treatment. (Am J Pathol 2019, 189: 753-761; https:// doi.org/10.1016/j.ajpath.2018.12.007)
\end{abstract}

Glucocorticoids (GCs) are anti-inflammatory molecules synthesized and secreted by the adrenal glands that exert significant influence on the physiological functioning of several systems, including adaptation to stress, metabolism, and regulation of immune responses. The signaling axis of GCs consists of the hypothalamic-pituitary-adrenal axis influenced by many factors, including neuroinflammation, physical stress, circadian rhythm, and negative feedback. GCs are used in the treatment of various diseases, such as asthma, rheumatoid arthritis, and systemic lupus erythematosus $^{1-4}$ with many reported side effects. ${ }^{5,6}$ Significantly, GC-induced osteoporosis (GIO) is the most predictable side effect and the commonest cause of secondary osteoporosis, leading to increased fracture risk in $30 \%$ to $50 \%$ of patients receiving GCs. ${ }^{5-9}$ Thus, there remains a significant unmet clinical need for the development of therapies to prevent and/ or treat GIO.
The central feature in the pathogenesis of GIO is the suppression of bone formation. Previous studies suggest that GCs decrease the number and function of osteoblasts by a reduction in osteoblastogenesis and impairment in osteoblastic differentiation and maturation. ${ }^{10,11}$ This consequently favors adipogenesis, most likely dictated by up-regulation of peroxisome proliferator-activated receptor $\gamma 2$, leading to increased bone marrow adiposity. ${ }^{12-15}$ In addition, GCs decrease osteoblast viability and activity, ultimately leading to a reduction in bone mass and compromised bone structure. ${ }^{11}$ Osteocytes are the other key players in GIO because GCs induce their apoptosis. ${ }^{16-18}$ This is likely achieved by the GC-mediated disruption of the osteocyte-lacunar-canalicular network,

Supported by funding from the BBSRC grant BB/I014608/1 (A.A.P.) and Arthritis Research UK grant 20581 (A.A.P.).

Disclosures: None declared. 
essential for osteocyte viability and maintenance of the bone's material properties. ${ }^{11}$ These changes may explain the impairment of the biomechanical properties in the surrounding bone ${ }^{16}$ and may account for the loss of bone strength that occurs before the loss of bone mineral density. ${ }^{19}$

One of the mechanisms by which GCs drive bone loss is by inhibition of the Wnt/ $\beta$-catenin signaling pathway, ${ }^{15,20-22}$ critical for the differentiation of mesenchymal cells toward mature osteoblasts, bone formation, and mechanoadaptive responses. ${ }^{11,16,23,24}$ A natural antagonist of Wnt signaling, sclerostin (Sost gene product), predominantly secreted by osteocytes, is a potent inhibitor of osteoblastic mineralization. ${ }^{25-27}$ Thus, its deficiency provokes marked increases in bone mass achieved by a range of targets, ${ }^{28-38}$ without any significant impact on osteocyte differentiation..$^{39,40}$

Several studies have reported contradictory results on the relationship between GC excess and sclerostin. ${ }^{41-45}$ Previous studies have reported that in vivo antisclerostin antibody treatment prevents the reduction in bone mass and strength induced by GC excess. ${ }^{41,42}$ Despite these established links between sclerostin levels and the prevention of GC-induced changes in bone mass, there remains controversy about how these links affect patients, in which there have been discordant reports of decreased serum sclerostin in patients after 1 week of GC treatment and increased serum sclerostin at later time points. ${ }^{43}$ Similar disparities in the levels of sclerostin are also seen in GC-related disease states, in which both increased and decreased levels are reported in patients with excess GCs. ${ }^{44,45}$ The reasons for these contradictory observations on the relationship between sclerostin and excess GCs are unclear, raising the question whether modulation of sclerostin function indeed counteracts the deleterious effect of endogenously raised GC levels on bone mass and strength.

We tested this possibility by determining whether genetically determined sclerostin deficiency was capable of rescuing the compromised bone mass that occurs with GC excess. To address this question, sclerostin-deficient mice were crossed with an established mouse model of GC excess because of an $N$-ethyl- $N$-nitrosourea-induced mutation in corticotropin-releasing hormone $(\mathrm{Crh}),{ }^{46}$ and the effects on bone mass and structure were evaluated along with detailed histopathologic analysis in a wide range of tissues. Our preclinical findings are relevant to ongoing clinical trials in which serious fatal cardiovascular adverse events were reported in patients receiving antisclerostin antibody. They particularly highlight a potential need for patient stratification to help realize the potential benefit of such treatment.

\section{Materials and Methods}

\section{Animals}

Frozen sperm from a male Sost knockout (KO) mouse in the C57BL/6NTac background was purchased from the Knockout
Mouse Project Repository at the University of California Davis, and used to fertilize ova from C57BL/6J wild-type (WT) mice as described previously ${ }^{39}$; hetero/haplozygosity was confirmed by genotyping. The mouse model for excessive circulating GC concentrations was a gift from Medical Research Council (Oxfordshire, UK) and was generated in C57BL/6J mice by an $N$-ethyl- $N$-nitrosourea-induced mutation in corticotropin-releasing hormone $(\mathrm{Crh})$ at $-120 \mathrm{bp}$ of the promoter region, resulting in a gain-of-function mutation $\left(\mathrm{Crh}^{+/-120}\right)$ and mated with $\mathrm{C} 3 \mathrm{H} / \mathrm{HeH}$ as described previously. ${ }^{46}$ Female Sost homozygous KO $\left(\right.$ Sost $\left.^{-1-}\right)$ mice were crossed with male $\mathrm{Crh}^{+/-120}$ to produce Sost-Crh ${ }^{+/-120}$ (Sost heterozygous/Crh heterozygous) and Sost ${ }^{+/-}$mice. Mice were housed in polypropylene cages under 12 hours light/dark cycle at $21 \pm 2{ }^{\circ} \mathrm{C}$ with free access to Rat/Mouse One maintenance $\operatorname{diet}$ (Special Diet Services, Witham, UK) and water ad libitum. The studies used only male mice throughout. All procedures complied with UK Animals (Scientific Procedures) Act 1986, were approved by the Royal Veterinary College's Ethics committee, and followed Animal Research: Reporting of In Vivo Experiments guidelines. ${ }^{47}$

\section{X-Ray MicroCT}

In vivo scanning of the entire right tibia at 1 month of age under $2 \%$ isoflurane-induced anesthesia and postmortem at 2 months of age were achieved with the use of a Skyscan 1176 $\mathrm{X}$-ray microcomputed tomography machine (Skyscan, Kontich, Belgium). The X-ray tube was operated at $40 \mathrm{kV}, 600$ $\mu \mathrm{A}$, with a voxel size of $9 \mu \mathrm{m}$, an exposure of $2000 \mathrm{~ms}$, and a rotation step of 0.800 degrees. The radiation dose from the microcomputed tomography (microCT) scanning was estimated to be approximately $500 \mathrm{mGy}$ for each scan, which has been proved to cause no significant effect on bone adaptations. ${ }^{48}$ Slices were reconstructed with the use of NRecon1.6; trabecular and whole bone analyses were performed as described previously. ${ }^{24}$ For morphometric trabecular analysis appearance of the trabecular bridge that connected the two primary spongiosa bone islands was set as a reference point for analysis of proximal tibia metaphyseal trabecular bone; 5\% of the total bone length from this point (toward diaphysis) was used. For cortical analysis, after segmentation, alignment, and removal of fibula a minimum threshold was used in Slice Geometry to calculate mass: cross-sectional area (CSA), mean cross-sectional thickness, second moment of area around minor axis, second moment of area around major axis, and predicted resistance to torsion along a central $70 \%$ portion of the entire tibia length excluding regions that contained trabecular bone.

\section{Histologic Analysis}

Tibia, heart, lungs, liver, spleen, kidneys, and brain were fixed in $4 \%$ formaldehyde (from paraformaldehyde Alfa Aesar Inc., Ward Hill, MA) and stored in $70 \%$ ethanol before routine processing into paraffin and production of 
slides sectioned at $4 \mu \mathrm{m}$ and stained with hematoxylin and eosin. Stained slides were evaluated by a board-certified veterinary pathologist (E.H., The Francis Crick Institute, London, UK). ${ }^{49}$ Total numbers of animals examined were Sost $^{+/+}$WT $(n=4)$, Sost $^{+/-}$heterozygous KO $(n=7)$, Sost $^{-1-}$ homozygous KO $(n=4), \mathrm{Crh}^{+/+}$WT $(n=4)$, $\mathrm{Crh}^{+/-120}$ heterozygous KO $(n=4)$, and Sost-Crh ${ }^{+/-120}$ heterozygous $(n=5)$ mice. In addition, Sost-Crh ${ }^{+/-120}$ $(n=3)$ mice which spontaneously died were stored in $70 \%$ ethanol and examined histologically. Hearts from these animals were examined by using multiple step levels and extensive sectioning throughout the block.

\section{Statistical Analysis}

Statistical analyses were performed with R, version 3.1.1 (R Foundation for Statistical Computing, Vienna, Austria; http://www.r-project.org, last accessed August 29, 2018). Measurements were summarized as means \pm SEM. Linear model (two-way analysis of variance) was used to determine the effects of age (1 and 2 months) and genotype (Sost heterozygous and homozygous as well as $\mathrm{Crh}$ heterozygous and double Sost-Crh heterozygous and their corresponding WT littermates) and their interaction on all phenotypic measurements. Bonferroni post hoc correction was performed for whole bone measurements. The statistical significance level was set at $5 \%$.

\section{Results}

\section{Sost Haploinsufficiency Does Not Rescue Compromised Bone Mass Induced by Excessive GCs}

The designed studies tested whether genetically determined Sost deficiency rescued low bone mass induced by excessive GCs in vivo. Trabecular bone was analyzed, and the entire tibial cortex was analyzed proximodistally in a nonbiased fashion at 1 and 2 months of age. Both age and genotype independently affected the cortical CSA, and significant interaction was evident between age and genotype along the entire tibial length (Figure 1). The detailed post hoc analyses at 1 month of age revealed, as expected, significantly higher CSA in Sost homozygous KO $\left(\right.$ Sost $\left.^{-1-}\right)$ mice than in Sost ${ }^{+/+}$WT mice (Figure 1) as well Sost ${ }^{-1-}$ mice compared with $\mathrm{Sost}^{+/-}$mice along the entire tibia. Unexpectedly, lower cortical CSA was observed in restricted regions of the tibia in Sost ${ }^{+/-}$mice compared with Sost $^{+/+}$WT littermates (Figure 1). At 2 months of age, CSA was significantly higher in Sost $t^{+/-}$mice than in Sost ${ }^{+/+}$WT mice between $15 \%$ and $85 \%$ of the length and also in $\mathrm{Sost}^{-1-}$ mice compared with Sost $^{+/+}$WT and Sost ${ }^{+/-}$mice across the entire tibial cortex.

Analysis of mice with excessive endogenous GCs at 1 month of age failed to find any significant differences in cortical CSA at any location along the tibia in WT $\mathrm{Crh}$ $\left(\mathrm{Crh}^{+/+} \mathrm{WT}\right)$, heterozygous $\mathrm{Crh}\left(\mathrm{Crh}^{+/-120}\right)$, or mice heterozygous for both $\mathrm{Crh}$ and Sost (Sost-Crh ${ }^{+1-120}$ ) (Figure 1). In contrast, in mice aged 2 months, CSA was, as expected, significantly lower in $\mathrm{Crh}^{+/-120}$ mice compared with $\mathrm{Crh}^{+/+}$WT mice and also lower in Sost-Crh ${ }^{+/-120}$ mice compared with $\mathrm{Crh}^{+/+}$mice between approximately $25 \%$ and $85 \%$ of the tibial length. Intriguingly, no significant rescue in the reduction of CSA was observed at any location in tibia from Sost-Crh ${ }^{+/-120}$ mice compared with $\mathrm{Crh}^{+/-120}$ mice. Evaluation of torsion, a measure of predicted resistance to torsion, showed identical trends, indicating that Sost haploinsufficiency also failed to rescue GC-induced decreases in the tibia's architectural strength (Supplemental Figure S1). Further interrogation of cortical bone revealed that mean cortical cross-sectional thickness (Supplemental Figure S2), second area around minor axis (Supplemental Figure S3), and around major axis (Supplemental Figure S4) also indicated that Sost haploinsufficiency failed to rescue $\mathrm{Crh}^{+/-120}$-induced compromise in cortical bone mass and architecture. Our evaluation of age-related changes in the WT mice of both Sost $^{-1-} \quad(\mathrm{C} 57 \mathrm{BL} / 6 \mathrm{NTac} / \mathrm{C} 57 \mathrm{BL} / 6 \mathrm{~J})$ and $\mathrm{Crh}^{+/-120}$ $(\mathrm{C} 57 \mathrm{BL} / 6 \mathrm{~J} / \mathrm{C} 3 \mathrm{H} / \mathrm{HeH})$ backgrounds revealed greater growth kinetics within the latter, between 1 and 2 months of age, suggesting that there was ample scope for any effects of the combined genetic manipulation to be realized (Supplemental Figure S5).

In addition to microCT analysis of cortical bone, tibial trabecular bone was analyzed. Percentage of bone volume [trabecular bone volume (BV)/trabecular total volume (TV)] was significantly greater in mice lacking both copies of Sost $\left(\right.$ Sost $\left.^{-1-}\right)$, whereas a trend that did not reach levels of statistical significance was observed for enhanced BV/TV in mice lacking a single copy $\left(\right.$ Sost $^{+-}$) (Figure 2A). This elevation of BV/TV in Sost ${ }^{-1-}$ mice was linked with enhanced BV, trabecular number, and thickness, and lower trabecular separation; neither of these variables alone reached statistical significance (Figure 2A). The analysis also showed a trend for lower trabecular BV/TV in mice with excess GCs $\left(\mathrm{Crh}^{+/-120}\right)$ and no significant modification of BV/TV in Sost-Crh ${ }^{+/-120}$ mice (Figure 2A). In agreement with the microCT data, detailed histologic evaluation of tibia structure revealed thicker cortices in tibiae from mice lacking either one $\left(\mathrm{Sost}^{+/-}\right)$or both $\left(\mathrm{Sost}^{-1-}\right)$ copies of functional Sost compared with tibia from Sost ${ }^{+/+}$ WT mice (Figure 2, B-G). Thinner cortices were also observed in $\mathrm{Crh}^{+/-120}$ mutant mice compared with tibiae from their $\mathrm{Crh}^{+/+}$WT littermates. In agreement with threedimensional quantification, tibiae from mice harboring both Sost $^{+/-}$and $\mathrm{Crh}^{+/-120}$ (Sost-Crh ${ }^{+/-120}$ ) were similar to $\mathrm{Crh}^{+/-120}$ mice, indicating a failure of Sost ${ }^{+/-}$to rescue the effects of GC excess on bone mass (Figure 2, E-G). Together, the detailed comparison of bone by both histology and microCT revealed at 2 months of age that i) both heteroand homozygous Sost-deficient mice exhibited significantly greater bone mass and predicted strength, ii) heterozygous $\mathrm{Crh}$ mutation led to a compromised bone mass and strength 


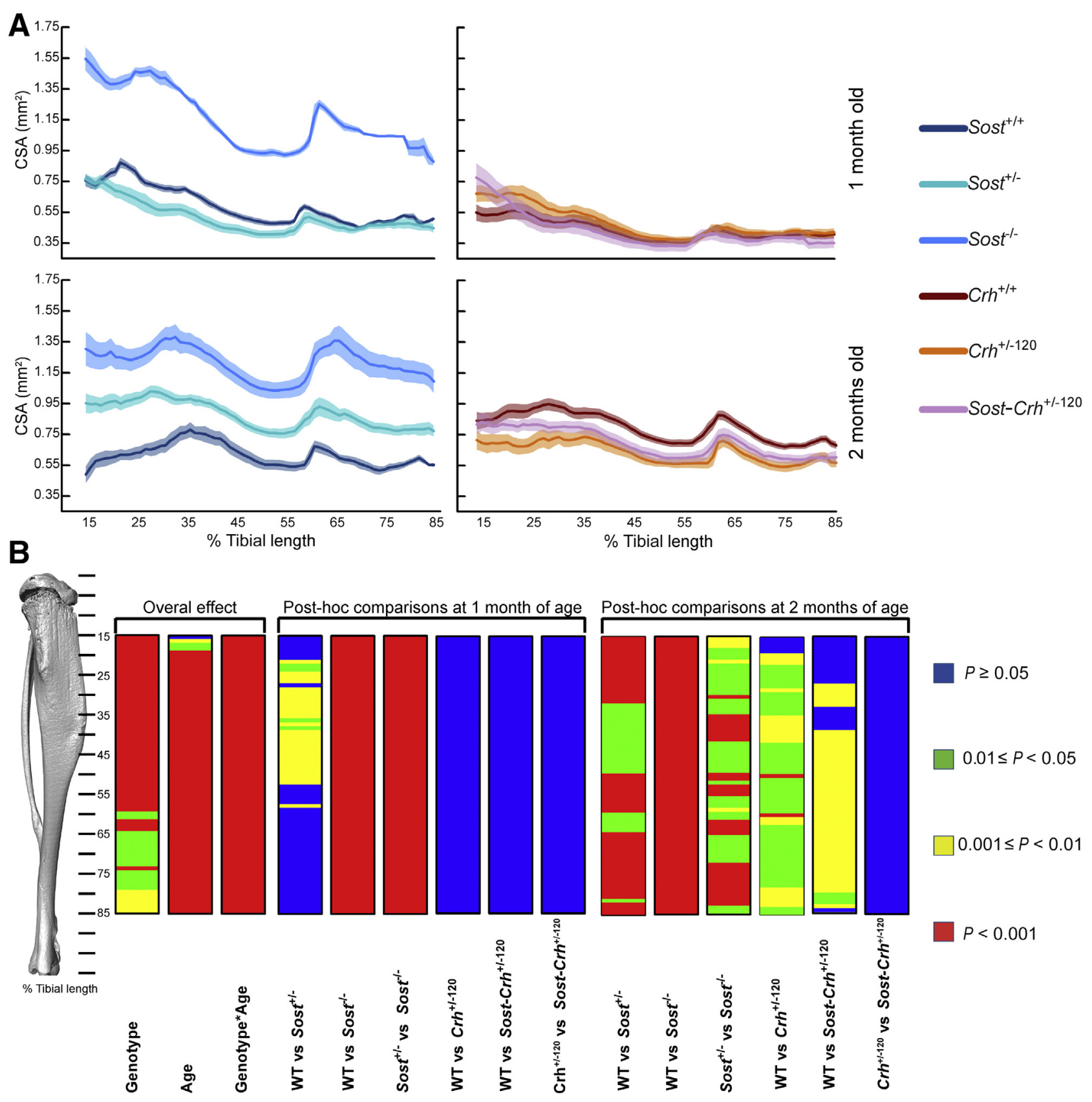

Figure 1 Sost haploinsufficiency does not rescue low bone cross-sectional area (CSA) induced by excessive glucocorticoids (GCs). A: Average CSA of Sost wild-type (WT) $\left(\right.$ Sost $\left.^{+/+}\right)$, Sost heterozygous knockout (KO) $\left(\right.$Sost $\left.{ }^{+/-}\right)$, Sost homozygous KO $\left(\right.$Sost $\left.^{-/-}\right)$, Crh WT $\left(\mathrm{Crh}^{+/+}\right)$, Crh heterozygous (Crh $\left.{ }^{+/-120}\right)$, and double Sost-Crh heterozygous (Sost-Crh ${ }^{+/-120}$ ) mice at 1 and 2 months of age. Lines represent the means; shading, the SEM. B: Graphic heatmap representation of statistical significance of the effect of genotype, age, their interactions as well as post hoc analysis along a $15 \%$ to $85 \%$ portion of the whole tibia length, excluding proximal and distal metaphyseal bone. Line graphs represent means \pm SEM (shadow). $n=8$ mice per group.

and, iii) Sost haploinsufficiency fails to rescue the compromised bone mass produced by excess GCs.

\section{Combined Sost Haploinsufficiency and $\mathrm{Crh}^{+/-120}$ Related GC Excess Provoke Peracute Lethal Cardiac Tamponade}

In the studies that examined potential rescue of excess GCrelated low bone mass by deletion of a single Sost allele, sudden, unprovoked, nonconvulsive death of approximately $10 \%$ of total Sost-Crh ${ }^{+/-}$offspring was observed between 1 to 2 months of age. No such incidences occurred in either $\mathrm{Crh}^{+/-120}$, $\mathrm{Sost}^{-/-}$mice or their respective WT littermates. To identify the cause of this sudden death, a comprehensive histopathologic examination of multiple tissues from all mouse strains was performed hematoxylin and eosin staining, which was scored with a semiquantitative grading system. Examination of the brain, kidney, liver, lung, and 

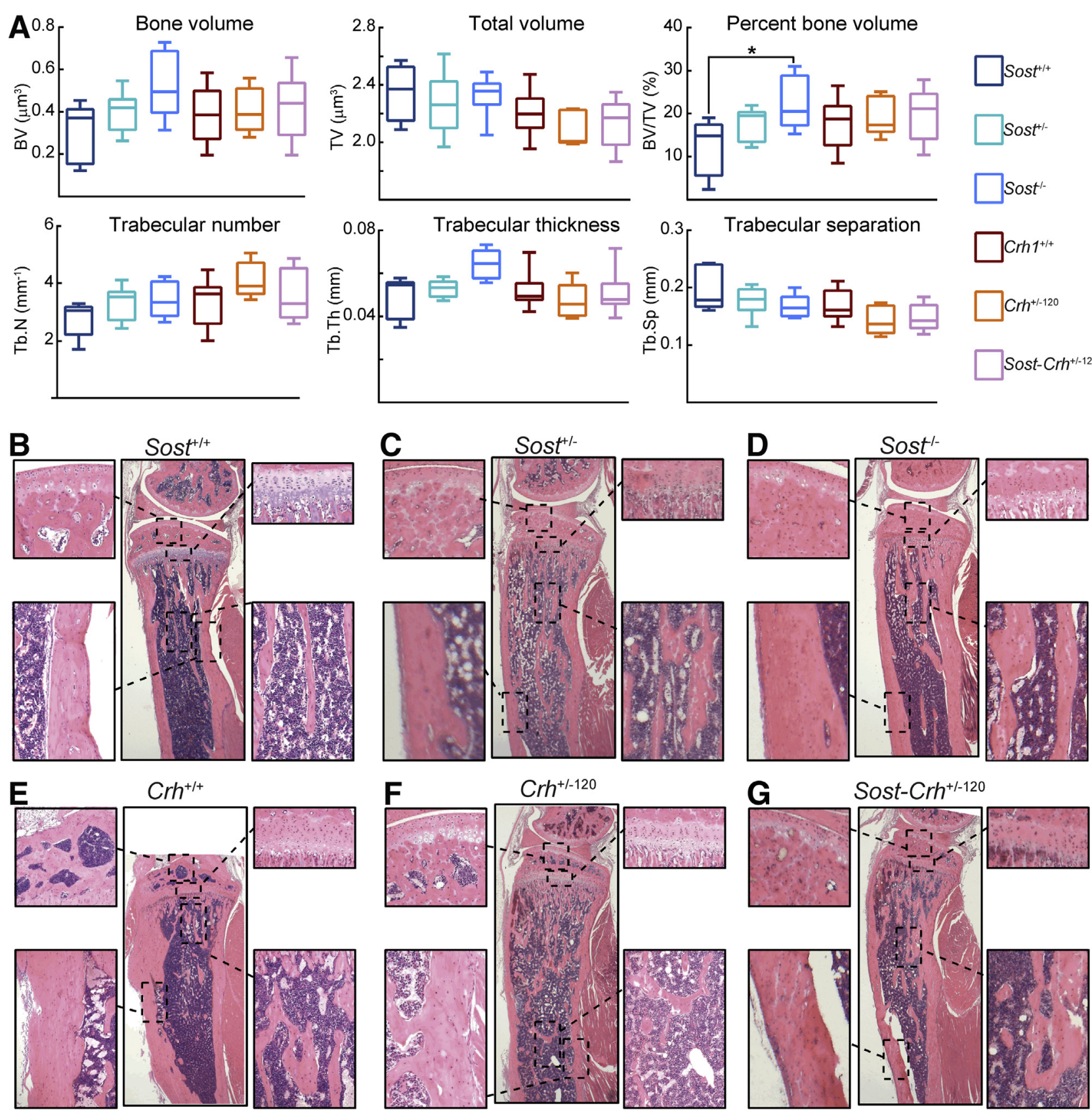

$\mathrm{Crh}^{+/+}$
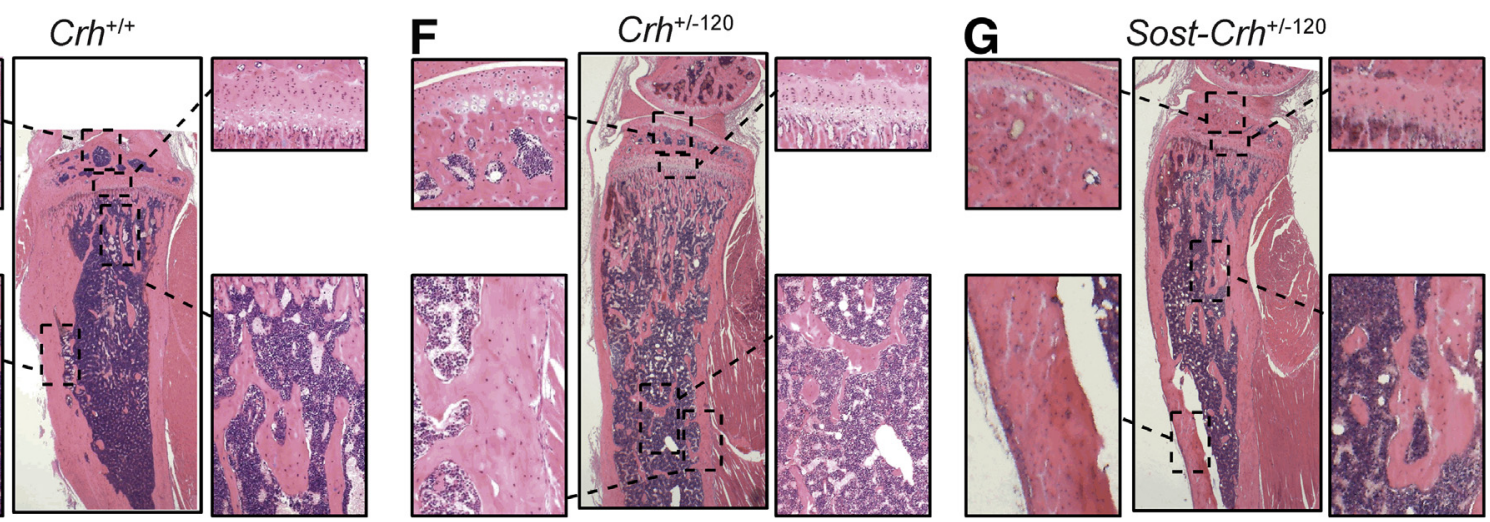

Figure 2 Trabecular bone phenotype of Sost wild-type (WT) (Sost $\left.{ }^{+/+}\right)$, Sost heterozygous knockout (K0) (Sost $\left.{ }^{+/-}\right)$, Sost homozygous K0 (Sost $\left.{ }^{-/-}\right)$, Crh WT $\left(\mathrm{Crh}^{+/+}\right), \mathrm{Crh}$ heterozygous $\left(\mathrm{Crh}^{+/-120}\right)$, and double Sost-Crh heterozygous $\left(\mathrm{Sost}_{-} \mathrm{Cr} h^{+/-120}\right)$ mice at 2 months of age. A: Ex vivo high-resolution analyses of the proximal metaphyseal tibia to determine trabecular bone volume (BV), trabecular total volume (TV), percentage of bone volume (BV/TV), trabecular number (Tb.N), trabecular thickness (Tb.Th), and trabecular separation (Tb.Sp). B-G: Representative hematoxylin and eosin-stained sections of tibia at 2 months of age.

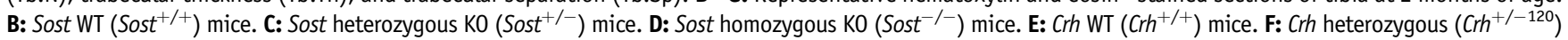
mice. G: Double Sost-Crh heterozygous (Sost-Crh ${ }^{+/-120}$ ) with corresponding higher magnification demonstrating the structural differences between groups. Data are expressed as means \pm SEM. $n=8$ mice per group. ${ }^{*} P<0.05$. Original magnification: $\times 2$ (B-G, main images); $\times 10$ (B-G, enlarged images)

spleen showed no signs of overt pathology in $\mathrm{Sost}^{+/+}$WT, Sost $^{+/-}$, Sost $^{-/}, \mathrm{Crh}^{+/+}$WT or $\mathrm{Crh}^{+/-120}$, or Sost-Crh ${ }^{+/-120}$ mice in which a propensity for sudden death was observed.

Intriguingly, evaluation of heart tissue in Sost-Crh ${ }^{+-120}$ mice with sudden death revealed all to have hemopericardium with a markedly expanded pericardial space that contained a large number of densely packed, homogenously distributed erythrocytes and compression of the right ventricular (Figure 3A) and right atrial lumen (Figure 3B) in all mice that experienced sudden death. Therefore, the cause of sudden death in these animals was considered to be due to peracute hemopericardium that led to cardiac tamponade. Hearts were examined at multiple step levels through the tissue to try to ascertain the origin of the hemorrhage; however, none could be identified. No significant findings were observed in the hearts of the remainder of the Sost- 


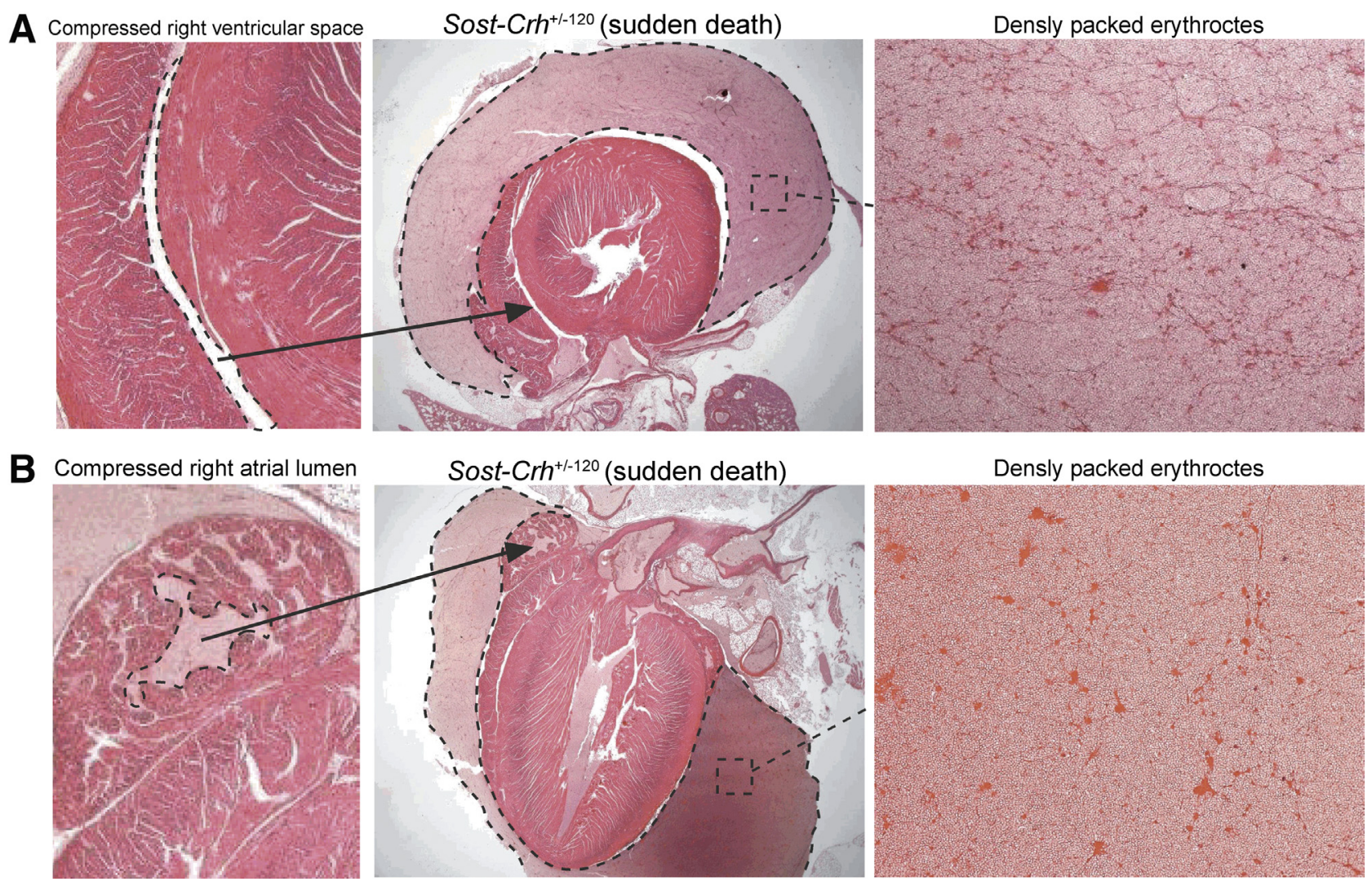

Figure 3 Sost haploinsufficiency together with excessive glucocorticoids (GCs) leads to peracute lethal cardiac tamponade. Two representative cases are displayed. A: Markedly expanded pericardial space (dashed line in middle panel) with a large number of densely packed, homogenously distributed erythrocytes and compressed right ventricular lumen. B: Hemopericardium (dashed line in middle panel) containing erythrocytes and a compressed right atrial lumen. Original magnification: $\times 2$ (A and $\mathbf{B}$, left panel); $\times 1.25$ (A and $\mathbf{B}$, middle panel); $\times 10$ (A and $\mathbf{B}$, right panel).

$\mathrm{Crh}^{+/-120}$ mice, or in any of the Sost $^{+/+} \mathrm{WT}$, Sost $^{+/-}$, Sost $^{-/-}, \mathrm{Crh}^{+/+} \mathrm{WT}$, and $\mathrm{Crh}^{+/-120}$ mice.

\section{Discussion}

Osteopenia because of excess GCs mainly involves a decrease in bone formation, secondary to the effects on the activity and viability of osteoblasts and osteocytes, which ultimately leads to an impairment in bone strength. One of the main mechanisms by which GCs achieve such deleterious outcome in bone is by antagonizing $\mathrm{Wnt} / \beta$-catenin signaling. Sclerostin, the product of the Sost gene, is the main negative regulator of the Wnt pathway in the skeleton. Thus, sclerostin normally acts to suppress the proformative and antiresorptive role of the Wnt signaling pathway. Herein, the hypothesis that the partial inactivation of sclerostin function by genetic manipulation will be capable of rescuing the low bone mass induced by high endogenous GC levels was tested.

In contrast, it was found instead that Sost haploinsufficiency was not capable of rescuing the low bone mass induced by high GC. These findings do not agree with previous studies which reported that transient antisclerostin antibody treatment rescued GC-induced low bone mass. ${ }^{41,42}$
It is possible that these dissimilar observations arise due solely to differences in experimental design and analysis. These studies undertook a nonbiased analysis of almost the entire tibial cortex adjusting for GC-induced divergence in bone length and thus ensure comparisons are made at precisely matched anatomic locations and volumes. Although Marenzana et $\mathrm{al}^{42}$ reported small, significant protective effects of antisclerostin antibody treatment against an exogenous GC-induced reduction in cortical bone volume at the femur mid-shaft, they did not find similar rescue of GCinduced reduction in bone length. The methods used, however, made no apparent correction for this growth retardation; thus, measurement of equivalent bone volumes was not ensured. ${ }^{42}$ An alternative explanation is that our studies encompass the developmental effect of excessive GCs and Sost haploinsufficiency, and it remains possible that this may diverge from the outcome of transient antisclerostin antibody treatment of adult mice that have induced GC excess. ${ }^{41,42}$

Sclerostin has long been considered an effective target for treating osteoporosis. The most recent phase 3 clinical trial of romosozumab (an antisclerostin antibody), to our knowledge, was however hampered by unforeseen, increased adverse cardiovascular risk, ${ }^{50}$ resulting in refusal to approve this treatment by the Food and Drug 
Administration. The finding that a combination of high endogenous GC levels together with Sost haploinsufficiency results in sudden death with histopathologic, marked hemopericardium, is therefore intriguing. The pericardial space in these mice was found to be markedly enlarged by densely packed erythrocytes with compression of the heart lumen, consistent with sudden death from cardiac tamponade.

To our knowledge, cardiac tamponade secondary to spontaneous hemopericardium has not been reported before in mice. In other species, causes of spontaneous hemopericardium occur because of rupture of the intra-pericardial portion of the aorta or pulmonary artery, rupture of a coronary vessel, cardiac rupture after an acute myocardial infarct or rupture of an atrium secondary to atrial thrombosis, blood dyscrasias, and neoplasia. The histologic examinations, however, did not localize the site of rupture/ hemorrhage or reveal an overt underlying pathology. Microscopic examination of the heart and major blood vessels in both affected and unaffected animals also failed to disclose any possible predisposing lesions such as aneurysm, congenital blood vessel anomaly, or cardiac disease.

Several possible explanations may clarify the underpinning mechanisms whereby sclerostin exerts a regulatory role in the cardiovascular system. Although sclerostin is reported to be expressed in the aorta, ${ }^{51-53}$ neither Sost KO mice in this study or others nor human patients with sclerosteosis or van Buchem's disease due to mutations in the SOST gene exhibit any greater risk of cardiovascular complications. ${ }^{54-57}$ Furthermore, a case study by van Lierop et $\mathrm{al}^{58}$ reported that GC treatment does not lead to adverse cardiovascular effects in a van Buchem high bone mass patient with mutation in the SOST gene. In addition, Sato et $\mathrm{al}^{59}$ reported that Sost homozygous KO mice treated with GCs maintain structural and material mechanical properties despite increased osteocyte apoptosis and that no cardiovascular complications were reported. It is possible that differences in our findings to those reported by aforementioned studies can be explained by the fact that the excess GCs present in $\mathrm{Crh}^{+/-120}$ mice during developmental and later life-course may affect multiple organs, including the cardiovascular system.

Other studies have also reported up-regulation of sclerostin in foci of vascular and valvular calcification. ${ }^{60-63}$ Our detailed histopathologic examinations were not able to find any signs of calcification in any mice in this study. This agrees with other animal studies showing that sclerostin is unlikely to be involved in vascular mineralization. ${ }^{52,64}$ No evidence suggests that sclerostin plays a causal role in cardiovascular disease, rather recent studies have reported an association between sclerostin levels and cardiovascular disorders. ${ }^{65-68}$ The precise function of sclerostin in the regulation of the cardiovascular system remains to be defined.

A limitation in our studies is the lack of any measured levels of circulatory sclerostin; thus, it remains to be verified that the Sost genetic haploinsufficiency in our studies is necessarily reflected in a change in expression levels. The middle level bone phenotype observed in the Sost haploinsufficient mice (either in mice with or without the $\mathrm{Crh}^{+/-120}$ mutation) in which true heterozygosity was also confirmed by genotyping makes it highly likely that sclerostin levels are modified accordingly. The levels might be lower in the Sost$\mathrm{Crh}^{+/-120}$ mice than in $\mathrm{Crh}^{+/-120}$ mice. Another limitation is that whether antisclerostin antibody-mediated blockade of sclerostin function is equivalent to genetic insufficiency cannot be predicted.

Nonetheless, the critical manifestation of Sost-deficiency combined with GC excess in our study is sporadic, sudden, unprovoked, and nonconvulsive death linked to peracute hemopericardium and cardiac tamponade. Tamponade has been linked to many conditions, including cancer, uremia, hypothyroidism, and pericarditis, where enlargement of pericardium arises gradually. ${ }^{69-72}$ No evidence for such conditions was found in this study. The rapid hemopericardium-related tamponade observed is more consistent with myocardial rupture, but this was not found on detailed pathologic examination using multiple step levels sectioned throughout the heart. The cause of this

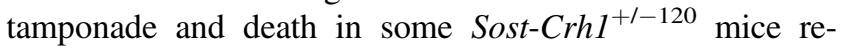
mains unexplained; this is confounded by a lack of any abnormal preceding changes evident in their living equivalents; no predisposing lesions, such as aneurysm, focal thinning, or disruption of the myocardium or coronary vessels were observed histologically in the unaffected animals. It is tempting to speculate on the likely mechanisms. Experiments that explore whether unrestricted Wnt signaling, due to Sost deficiency, interacts with regulators of inflammatory processes, as seen in circumstances such as GC excess, may explain such serious adverse cardiovascular events. These findings that use mouse preclinical models, therefore, prompt further studies aimed at deciphering their clinical significance and the underpinning molecular mechanisms by which GC-induced osteopenia might be better-targeted without risk of cardiovascular side effects.

\section{Acknowledgments}

The $C r h$ mouse model for excessive circulating glucocorticoid (GC) concentrations was a gift from Medical Research Council (Oxfordshire, UK). We thank Professor Cheryl Scudamore for highlighting the availability of these $\mathrm{Crh}$ mice as a robust model of GC excess and Prof Chantal Chenu for critical reading of the manuscript.

B.J., E.H., M.H., and A.A.-J. collected data; B.J., E.H., and A.A.P. wrote the manuscript; all authors approved the manuscript.

\section{Supplemental Data}

Supplemental material for this article can be found at https://doi.org/10.1016/j.ajpath.2018.12.007. 


\section{References}

1. Buttgereit F, Burmester G-R, Lipworth BJ: Optimised glucocorticoid therapy: the sharpening of an old spear. Lancet 2005, 365:801-803

2. Ogoshi T, Hagino H, Fukata S, Tanishima S, Okano T, Teshima R: Influence of glucocorticoid on bone in 3-, 6-, and 12-month-old rats as determined by bone mass and histomorphometry. Mod Rheumatol 2008, 18:552-561

3. McLaughlin F, Mackintosh J, Hayes BP, McLaren A, Uings IJ, Salmon P, Humphreys J, Meldrum E, Farrow SN: Glucocorticoidinduced osteopenia in the mouse as assessed by histomorphometry, microcomputed tomography, and biochemical markers. Bone 2002, 30:924-930

4. Bultink IE, Baden M, Lems WF: Glucocorticoid-induced osteoporosis: an update on current pharmacotherapy and future directions. Expert Opin Pharmacother 2013, 14:185-197

5. Humphrey EL, Williams JH, Davie MW, Marshall MJ: Effects of dissociated glucocorticoids on OPG and RANKL in osteoblastic cells. Bone 2006, 38:652-661

6. Schäcke H, Döcke W-D, Asadullah K: Mechanisms involved in the side effects of glucocorticoids. Pharmacol Ther 2002, 96:23-43

7. Chen Z, Xue J, Shen T, Mu S, Fu Q: Curcumin alleviates glucocorticoid-induced osteoporosis through the regulation of the Wnt signaling pathway. Int J Mol Med 2016, 37:329-338

8. Adachi JD, Bensen WG, Hodsman AB: Corticosteroid-induced osteoporosis. Semin Arthritis Rheum 1993, 22:375-384

9. Saag KG: Low-dose corticosteroid therapy in rheumatoid arthritis: balancing the evidence. Am J Med 1997, 103:31S-39S

10. Canalis E: Wnt signalling in osteoporosis: mechanisms and novel therapeutic approaches. Nat Rev Endocrinol 2013, 9:575-583

11. Canalis E, Mazziotti G, Giustina A, Bilezikian J: Glucocorticoidinduced osteoporosis: pathophysiology and therapy. Osteoporos Int 2007, 18:1319-1328

12. Hoeppner LH, Secreto FJ, Westendorf JJ: Wnt signaling as a therapeutic target for bone diseases. Expert Opin Ther Targets 2009, 13: 485-496

13. Yao W, Cheng Z, Busse C, Pham A, Nakamura MC, Lane NE: Glucocorticoid excess in mice results in early activation of osteoclastogenesis and adipogenesis and prolonged suppression of osteogenesis: a longitudinal study of gene expression in bone tissue from glucocorticoid-treated mice. Arthritis Rheum 2008, 58:1674-1686

14. Cavagnini F, Croci M, Putignano P, Petroni M, Invitti C: Glucocorticoids and neuroendocrine function. Int $\mathrm{J}$ Obes Relat Metab Disord 2000, 24 Suppl 2:S77-S79

15. Georgiou KR, Hui SK, Xian CJ: Regulatory pathways associated with bone loss and bone marrow adiposity caused by aging, chemotherapy, glucocorticoid therapy and radiotherapy. Am J Stem Cells 2012, 1: 205-224

16. Compston J: Management of glucocorticoid-induced osteoporosis. Nat Rev Rheumatol 2010, 6:82-88

17. Bellido T: Antagonistic interplay between mechanical forces and glucocorticoids in bone: a tale of kinases. J Cell Biochem 2010, 111: $1-6$

18. Plotkin LI, Manolagas SC, Bellido T: Glucocorticoids induce osteocyte apoptosis by blocking focal adhesion kinase-mediated survival. Evidence for inside-out signaling leading to anoikis. J Biol Chem 2007, 282:24120-24130

19. Weinstein RS: Glucocorticoid-induced bone disease. Primer on the Metabolic Bone Diseases and Disorders of Mineral Metabolism. ed 8. Hoboken, NJ, American Society for Bone and Mineral Research, 2013. pp. 473-481

20. Ohnaka K: Wnt signaling and glucocorticoid-induced osteoporosis Japanese. Clin Calcium 2006, 16:1812-1816

21. Yao W, Cheng Z, Pham A, Busse C, Zimmermann EA, Ritchie RO, Lane NE: Glucocorticoid-induced bone loss in mice can be reversed by the actions of parathyroid hormone and risedronate on different pathways for bone formation and mineralization. Arthritis Rheum 2008, 58:3485-3497

22. Gourlay M, Franceschini N, Sheyn Y: Prevention and treatment strategies for glucocorticoid-induced osteoporotic fractures. Clin Rheumatol 2007, 26:144-153

23. Javaheri B, Stern AR, Lara N, Dallas M, Zhao H, Liu Y, Bonewald LF, Johnson ML: Deletion of a single $\beta$-catenin allele in osteocytes abolishes the bone anabolic response to loading. J Bone Miner Res 2014, 29:705-715

24. Javaheri B, Carriero A, Wood M, De Souza R, Lee PD, Shefelbine S, Pitsillides AA: Transient peak-strain matching partially recovers the age-impaired mechanoadaptive cortical bone response. Sci Rep 2018, 8:6636

25. Weivoda MM, Youssef SJ, Oursler MJ: Sclerostin expression and functions beyond the osteocyte. Bone 2017, 96:45-50

26. Balemans W, Cleiren E, Siebers U, Horst J, Van Hul W: A generalized skeletal hyperostosis in two siblings caused by a novel mutation in the SOST gene. Bone 2005, 36:943-947

27. Lin C, Jiang X, Dai Z, Guo X, Weng T, Wang J, Li Y, Feng G, Gao X, He L: Sclerostin mediates bone response to mechanical unloading through antagonizing Wnt/beta-catenin signaling. J Bone Miner Res 2009, 24:1651-1661

28. Reya T, Clevers H: Wnt signalling in stem cells and cancer. Nature 2005, 434:843-850

29. Kato M, Patel MS, Levasseur R, Lobov I, Chang BH, Glass DA II, Hartmann C, Li L, Hwang TH, Brayton CF, Lang RA, Karsenty G, Chan L: Cbfa1-independent decrease in osteoblast proliferation, osteopenia, and persistent embryonic eye vascularization in mice deficient in Lrp5, a Wnt coreceptor. J Cell Biol 2002, 157:303-314

30. Bodine PV, Zhao W, Kharode YP, Bex FJ, Lambert A-J, Goad MB, Gaur T, Stein GS, Lian JB, Komm BS: The Wnt antagonist secreted frizzled-related protein-1 is a negative regulator of trabecular bone formation in adult mice. Mol Endocrinol 2004, 18:1222-1237

31. Babij P, Zhao W, Small C, Kharode Y, Yaworsky PJ, Bouxsein ML, Reddy PS, Bodine PV, Robinson JA, Bhat B, Morzolf J, Moran RA, Bex F: High bone mass in mice expressing a mutant LRP5 gene. J Bone Miner Res 2003, 18:960-974

32. Glass DA II, Bialek P, Ahn JD, Starbuck M, Patel MS, Clevers H, Taketo MM, Long F, McMahon AP, Lang RA, Karsenty G: Canonical Wnt signaling in differentiated osteoblasts controls osteoclast differentiation. Dev Cell 2005, 8:751-764

33. Holmen SL, Zylstra CR, Mukherjee A, Sigler RE, Faugere MC, Bouxsein ML, Deng L, Clemens TL, Williams BO: Essential role of beta-catenin in postnatal bone acquisition. J Biol Chem 2005, 280: $21162-21168$

34. Johnson ML, Harnish K, Nusse R, Van Hul W: LRP5 and Wnt signaling: a union made for bone. J Bone Miner Res 2004, 19: $1749-1757$

35. Armstrong VJ, Muzylak M, Sunters A, Zaman G, Saxon LK, Price JS, Lanyon LE: Wnt/beta-catenin signaling is a component of osteoblastic bone cell early responses to load-bearing and requires estrogen receptor alpha. J Biol Chem 2007, 282:20715-20727

36. Bex F, Green P, Marzolf J, Babij P, Yaworsky P, Kharode Y: The human LRP5 G171V mutation in mice alters the skeletal response to limb unloading but not to ovariectomy. J Bone Miner Res 2003, $18: \mathrm{S} 60$

37. Robinson JA, Chatterjee-Kishore M, Yaworsky PJ, Cullen DM, Zhao W, Li C, Kharode Y, Sauter L, Babij P, Brown EL, Hill AA, Akhter MP, Johnson ML, Recker RR, Komm BS, Bex FJ: Wnt/betacatenin signaling is a normal physiological response to mechanical loading in bone. J Biol Chem 2006, 281:31720-31728

38. Sawakami K, Robling AG, Ai M, Pitner ND, Liu D, Warden SJ, Li J, Maye P, Rowe DW, Duncan RL, Warman ML, Turner CH: The Wnt co-receptor LRP5 is essential for skeletal mechanotransduction but not for the anabolic bone response to parathyroid hormone treatment. J Biol Chem 2006, 281:23698-23711 
39. Mosey H, Núñez JA, Goring A, Clarkin CE, Staines KA, Lee PD, Pitsillides AA, Javaheri B: Sost deficiency does not alter bone's lacunar or vascular porosity in Mice. Front Mater 2017, 4:27

40. Balemans W, Ebeling M, Patel N, Van Hul E, Olson P, Dioszegi M, Lacza C, Wuyts W, Van Den Ende J, Willems P, Paes-Alves AF, Hill S, Bueno M, Ramos FJ, Tacconi P, Dikkers FG, Stratakis C, Lindpaintner K, Vickery B, Foernzler D, Van Hul W: Increased bone density in sclerosteosis is due to the deficiency of a novel secreted protein (SOST). Hum Mol Genet 2001, 10:537-543

41. Yao W, Dai W, Jiang L, Lay E-A, Zhong Z, Ritchie R, Li X, Ke H, Lane N: Sclerostin-antibody treatment of glucocorticoid-induced osteoporosis maintained bone mass and strength. Osteoporos Int 2016, 27:283-294

42. Marenzana M, Greenslade K, Eddleston A, Okoye R, Marshall D, Moore A, Robinson MK: Sclerostin antibody treatment enhances bone strength but does not prevent growth retardation in young mice treated with dexamethasone. Arthritis Rheum 2011, 63:2385-2395

43. Gifre L, Ruiz-Gaspa S, Monegal A, Nomdedeu B, Filella X, Guanabens N, Peris P: Effect of glucocorticoid treatment on Wnt signalling antagonists (sclerostin and Dkk-1) and their relationship with bone turnover. Bone 2013, 57:272-276

44. Belaya ZE, Rozhinskaya LY, Melnichenko GA, Solodovnikov AG, Dragunova NV, Iljin AV, Dzeranova LK, Dedov II: Serum extracellular secreted antagonists of the canonical Wnt/ $\beta$-catenin signaling pathway in patients with Cushing's syndrome. Osteoporos Int 2013, 24:2191-2199

45. Van Lierop AH, van der Eerden AW, Hamdy NA, Hermus AR, den Heijer M, Papapoulos SE: Circulating sclerostin levels are decreased in patients with endogenous hypercortisolism and increase after treatment. J Clin Endocrinol Metab 2012, 97:E1953-E1957

46. Bentley L, Esapa CT, Nesbit MA, Head RA, Evans H, Lath D, Scudamore CL, Hough TA, Podrini C, Hannan FM, Fraser WD, Croucher BI, Brown MA, Brown SD, Cox RD, Thakker RV: An N-ethyl-N-nitrosourea induced corticotropin-releasing hormone promoter mutation provides a mouse model for endogenous glucocorticoid excess. Endocrinology 2014, 155:908-922

47. Kilkenny C, Browne WJ, Cuthill IC, Emerson M, Altman DG: Improving bioscience research reporting: the ARRIVE guidelines for reporting animal research. PLoS Biol 2010, 8:e1000412

48. Laperre K, Depypere M, van Gastel N, Torrekens S, Moermans K, Bogaerts R, Maes F, Carmeliet G: Development of micro-CT protocols for in vivo follow-up of mouse bone architecture without major radiation side effects. Bone 2011, 49:613-622

49. Scudamore CL: A Practical Guide to the Histology of the Mouse. Hoboken, NJ, John Wiley \& Sons, 2014

50. Saag KG, Petersen J, Brandi ML, Karaplis AC, Lorentzon M, Thomas T, Maddox J, Fan M, Meisner PD, Grauer A: Romosozumab or alendronate for fracture prevention in women with osteoporosis. N Engl J Med 2017, 377:1417-1427

51. Didangelos A, Yin X, Mandal K, Baumert M, Jahangiri M, Mayr M: Proteomic characterization of extracellular space components in the human aorta. Mol Cell Proteomics 2010, 9:2048-2062

52. Chouinard L, Felx M, Mellal N, Varela A, Mann P, Jolette J, Samadfam R, Smith SY, Locher K, Buntich S, Ominsky MS, Pyrah I, Boyce RW: Carcinogenicity risk assessment of romosozumab: a review of scientific weight-of-evidence and findings in a rat lifetime pharmacology study. Regul Toxicol Pharmacol 2016, 81:212-222

53. Brunkow ME, Gardner JC, Van Ness J, Paeper BW, Kovacevich BR, Proll S, Skonier JE, Zhao L, Sabo P, Fu Y-H, Alisch RS, Gillett L, Colbert T, Tacconi P, Galas D, Hamersma H, Beighton P, Mulligan J: Bone dysplasia sclerosteosis results from loss of the SOST gene product, a novel cystine knot-containing protein. Am J Hum Genet 2001, 68:577-589

54. Vanhoenacker FM, Balemans W, Tan GJ, Dikkers FG, De Schepper AM, Mathysen DG, Bernaerts A, Van Hul W: Van Buchem disease: lifetime evolution of radioclinical features. Skeletal Radiol 2003, 32:708-718
55. Van Buchem FSP, Prick JJG, Jaspar H: Hyperostosis Corticalis Generalisata Familiaris (van Buchem's Disease). Amsterdam, Excerpta Medica, 1976

56. Li X, Ominsky MS, Niu QT, Sun N, Daugherty B, D’Agostin D, Kurahara C, Gao Y, Cao J, Gong J, Asuncion F, Barrero M, Warmington K, Dwyer D, Stolina M, Morony S, Sarosi I, Kostenuik PJ, Lacey DL, Simonet WS, Ke HZ, Paszty C: Targeted deletion of the sclerostin gene in mice results in increased bone formation and bone strength. J Bone Miner Res 2008, 23:860-869

57. Hamersma H, Gardner J, Beighton P: The natural history of sclerosteosis. Clin Genet 2003, 63:192-197

58. van Lierop AH, Hamdy NA, Papapoulos SE: Glucocorticoids are not always deleterious for bone. J Bone Miner Res 2010, 25:2796-2800

59. Sato AY, Cregor M, Delgado-Calle J, Condon KW, Allen MR, Peacock M, Plotkin LI, Bellido T: Protection from glucocorticoidinduced osteoporosis by anti-catabolic signaling in the absence of Sost/Sclerostin. J Bone Miner Res 2016, 31:1791-1802

60. Zhu D, Mackenzie NCW, Millan JL, Farquharson C, MacRae VE: The appearance and modulation of osteocyte marker expression during calcification of vascular smooth muscle cells. PloS One 2011, 6:e19595

61. Rukov JL, Gravesen E, Mace ML, Hofman-Bang J, Vinther J, Andersen CB, Lewin E, Olgaard K: Effect of chronic uremia on the transcriptional profile of the calcified aorta analyzed by RNA sequencing. Am J Physiol Renal Physiol 2016, 310:F477-F491

62. Kramann R, Kunter U, Brandenburg VM, Leisten I, Ehling J, Klinkhammer BM, Knüchel R, Floege J, Schneider RK: Osteogenesis of heterotopically transplanted mesenchymal stromal cells in rat models of chronic kidney disease. J Bone Miner Res 2013, 28:2523-2534

63. Brandenburg VM, Kramann R, Koos R, Krüger T, Schurgers L, Mühlenbruch G, Hübner S, Gladziwa U, Drechsler C, Ketteler M: Relationship between sclerostin and cardiovascular calcification in hemodialysis patients: a cross-sectional study. BMC Nephrol 2013, 14:219

64. Ominsky MS, Boyd SK, Varela A, Jolette J, Felx M, Doyle N, Mellal N, Smith SY, Locher K, Buntich S, Pyrah I, Boyce RW: Romosozumab improves bone mass and strength while maintaining bone quality in ovariectomized cynomolgus monkeys. J Bone Miner Res 2017, 32:788-801

65. Novo-Rodríguez C, García-Fontana B, Luna-Del Castillo JDD, Andújar-Vera F, Ávila-Rubio V, García-Fontana C, MoralesSantana S, Rozas-Moreno P, Muñoz-Torres M: Circulating levels of sclerostin are associated with cardiovascular mortality. PloS One 2018, 13:e199504

66. Gaudio A, Fiore V, Rapisarda R, Sidoti MH, Xourafa A, Catalano A, Tringali G, Zanoli L, Signorelli SS, Fiore CE: Sclerostin is a possible candidate marker of arterial stiffness: results from a cohort study in Catania. Mol Med Rep 2017, 15:3420-3424

67. Krishna SM, Seto S-W, Jose RJ, Li J, Morton SK, Biros E, Wang Y, Nsengiyumva V, Lindeman JH, Loots GG, Rush CM, Craig JM, Golledge J: Wnt signaling pathway inhibitor sclerostin inhibits angiotensin II-induced aortic aneurysm and atherosclerosis. Arterioscler Thromb Vasc Biol 2017, 37:553-566

68. Gaudio A, Privitera F, Pulvirenti I, Canzonieri E, Rapisarda R, Fiore CE: The relationship between inhibitors of the Wnt signalling pathway (sclerostin and Dickkopf-1) and carotid intima-media thickness in postmenopausal women with type 2 diabetes mellitus. Diab Vasc Dis Res 2014, 11:48-52

69. Okamoto H, Shinkai T, Yamakido M, Saijo N: Cardiac tamponade caused by primary lung cancer and the management of pericardial effusion. Cancer 1993, 71:93-98

70. Baldwin JJ, Edwards JE: Uremic pericarditis as a cause of cardiac tamponade. Circulation 1976, 53:896-901

71. Manolis AS, Varriale P, Ostrowski RM: Hypothyroid cardiac tamponade. Arch Intern Med 1987, 147:1167-1169

72. Kabukcu M, Demircioglu F, Yanik E, Basarici I, Ersel F: Pericardial tamponade and large pericardial effusions: causal factors and efficacy of percutaneous catheter drainage in 50 patients. Tex Heart Inst J 2004, 31:398-403 